\title{
Editorial
}

\section{China: uma arte para dois mundos}

\section{China: one art for two worlds}

\begin{abstract}
André Bueno ${ }^{1}$
${ }^{1}$ Doutorado em filosofia pela Universidade Gama Filho (UGF). Professor adjunto do curso de História da Universidade do Estado do Rio de Janeiro (UERJ) e professor do programa de Pós-graduação em História da Universidade do Estado do Rio de Janeiro (PPGH/UERJ) E-mail: orientalismo@gmail.com
\end{abstract}

Recebido em: 2 junho de 2020; Aceito em: 3 de agosto de 2019

DOI: $10.12957 /$ nearco.2020.57517

\section{Resumo}

Nesse breve artigo, examinaremos a relação entre escrita, arte e religiosidade na China antiga, analisando como as formas de expressão simbólicas serviram como meios de representação de ideias e evocação espiritual. Nossa análise será feita no contexto da dinastia Zhou, e examinaremos o caso da pintura "O Cavalheiro que cavalga o dragão", encontrada em tumba do século 3 AEC.

Palavras chave: Arte: escrita chinesa; China antiga; religiosidade chinesa; dinastia Zhou.

\section{Abstract}

In this brief article, we will examine the relationship between writing, art and religiosity in ancient China, analyzing how symbolic forms of expression served as means of representation of ideas and spiritual evocation. Our analysis will be done in the context of the Zhou dynasty, and we will examine the case of the painting "The Gentleman who rides the dragon", found in the tomb of the 3rd century BC.

Keywords: Art: Chinese writing; Ancient China; Chinese religiosity; Zhou dynasty.

\section{Introdução}

Analisar a arte chinesa envolve, antes de tudo, definir um meio em como abordála. De início, o próprio termo 'Arte', no sentido de Artes Plásticas, é uma criação latina que não encontra um similar direto na língua chinesa. Isso não implica, contudo, que os chineses não tenham criado suas formas autóctones de expressão artística; ao contrário, 
ISSN 1982-8713

os chineses desenvolveram uma longa e contínua tradição, amplamente discutida e codificada, que colocava o plano de apreciação estética como um dos objetos centrais do seu pensamento filosófico (embora, novamente, 'Estética' e 'Filosofia' sejam termos ocidentais, que não necessariamente encontram equivalentes diretos na língua chinesa). Usualmente, o termo Yi 藝 tem sido empregado como sinônimo de "arte", mas com determinados cuidados que envolvem sua antiguidade e polissemia (Sinedino, 2015)

Como, porém, nossos instrumentos teóricos podem servir ao entendimento de uma tradição artística tão distinta da nossa? Afinal, essa é a história das expressões artísticas de uma civilização que não parou de se desenvolver continuamente desde o século 22 AEC - apenas para tomarmos como referência os núcleos urbanos mais antigos conhecidos pela arqueologia (Barnes, 1999, p.187-92). De certo modo, torna-se quase necessário 'aprisionar' o outro - no caso, o chinês - aos nossos conceitos para não patinar, justamente, nas interpretações plurívocas.

Essa inserção beira um artificialismo incômodo: como adaptar os movimentos da arte chinesa aos períodos organizados como "antigo, medieval, moderno, etc.", já que a cronologia da China não se ajusta as eras históricas europeias? Além disso, há uma condição fundamental: e como os chineses organizaram o entendimento histórico de suas próprias expressões artísticas? Quais suas definições, métodos, teorias, classificações? Ao constatarmos que os chineses escreveram tratados sobre música, literatura e pintura, somos obrigados a reconhecer que uma abordagem consciente sobre a arte chinesa exige conhecimento de seus próprios textos e ideias, o que ocasionalmente afasta incursões mais profundas de especialistas menos preparados.

Os sinólogos e os estudiosos de arte chinesa vêm tentando analisar (e apresentar) essa tradição de três modos distintos, calcados em suas bases ocidentais, mas levando em conta, na medida do possível, os discursos dos próprios chineses. No primeiro, tenta-se classificar e estudar os objetos artísticos chineses por suas expressões formais e técnicas, quer sejam: pintura, cerâmica, escultura, música, caligrafia, etc. 
ISSN 1982-8713

(Lion-Goldschmidt e Moreau-Gobard, 1980) Nesse caso, busca-se analisar um conjunto específico de expressões artísticas, o que pode limitar a compreensão das tendências estéticas de um determinado contexto. Isso fica claro, por exemplo, quando ficamos sabendo que textos sobre pintura, como o Guhua Pinlu 古畫品錄, eram utilizados pelos chineses para explicar teoricamente as formas e métodos de outros campos artísticos (Lin, 1967, p.34-5).

Outro caminho tem sido analisar a arte chinesa dentro do próprio contexto, buscando identificar essas marcações estéticas (ou, a "moda") presentes em suas mais diversas manifestações. Isso tem sido bastante eficaz para compreender as ideologias imagéticas empreendidas pelas dinastias chinesas. Graças a uma coleção significativa de vestígios arqueológicos, conseguimos reconhecer tendências presentes numa determinada época, o que nos permite generalizações razoavelmente seguras, tais como a importância do bronze na Dinastia Shang 商 (1766-1046 AEC), a cerâmica tricolor da Dinastia Tang 唐 (618-907 EC) ou as multicoloridas porcelanas Ming 明 (1368-1644 EC) (Watson, 2000 e Scarpari, 2006). Novamente, porém, essa organização apresenta dois problemas: a) há certa dificuldade em concatenar as continuidades na elaboração do pensamento artístico de uma época para outra; os mesmos já citados cânones da pintura chinesa, por exemplo, atravessaram séculos e dinastias; b) tais generalizações são provenientes dos materiais de que dispomos, o que significa dizer que a descoberta de novos sítios arqueológicos pode modificar, no futuro, os aspectos gerais e/ou específicos dessas mesmas classificações. Para citar outro caso, a descoberta da tumba de Qinshi Huangdi 秦始皇帝 em 1974 - que revelou o inédito exército dos guerreiros de terracota, e cujas proporções e propósitos eram objeto de especulação para a arqueologia chinesa - modificou radicalmente as percepções vigentes sobre a produção artística no passado chinês (Portal, 2007).

Por fim, o terceiro modo de analisar a arte chinesa tem sido o de tentar entendêla e apresentá-la por suas próprias classificações (Joppert, 1984 e 2015). Isso significa uma experiência notável de deslocamento em relação as nossas referências 
ISSN 1982-8713

logocêntricas, mas que muitas vezes torna distante, ou quase inacessível, uma compreensão mais direta, por parte do público menos especializado, do que poderiam ser as formas artísticas chinesas. Um exemplo clássico é o do método chinês de classificar porcelanas por um sistema sonoro, pouco conhecido fora do círculo de peritos em cerâmica. Do mesmo modo, na concepção artística chinesa, a cópia de pinturas famosas é um excelente meio de aprendizado; uma cópia bem feita é um sinal de domínio das técnicas; e por fim, que um grande número de cópias consagra o original, ao invés de banalizá-lo, criando uma verdadeira cultura da cópia (Han, 2016).

Cumpre fazer, ainda, uma consideração importante: a própria questão da preservação dos objetos artísticos chineses. A tradição chinesa deslocou o problema da conservação da obra de arte em si - na visão chinesa, sempre perecível, e fada a destruição num mundo regido pela mutação - pela conservação dos métodos pelos quais a obra foi produzida, permitindo assim uma (teórica) reprodução contínua de sua forma e beleza originais (Bueno, 2010c). Simon Leys cita-nos, por exemplo, a famosa peça caligráfica "Prefácio aos poemas compostos no Pavilhão das Orquídeas" (Lantingji $X u$ 蘭亭集序) de Wang Xizhi 王羲之 (303-361 EC), da qual hoje nos restam apenas cópias, que inspirou profundamente o imaginário artístico chinês - mesmo que não tenha restado o original, e que haja dúvidas importantes sobre sua autoria (Leys, 2005, p.25-30). Esse apontamento é bastante significativo: na transição de um período dinástico para outro, quais fatores afinal determinam a eleição dos símbolos? O que se modifica no plano das ideais para, assim, se transformarem as formas aparentes dos objetos artísticos? O que se preserva do método de produção anterior - e o que muda? Obviamente, podemos esboçar explicações para tais mudanças, pois a China está longe de ser uma civilização imóvel: mas esse fator nos revela, novamente, os cuidados que devemos ter em escolher nossos ângulos de abordagem.

Nesse breve artigo, buscaremos apresentar um aspecto específico da arte chinesa, levando em conta as questões anteriormente discutidas: a relação das expressões artísticas chinesas - notadamente da pintura e da caligrafia - com suas 
crenças numa existência espiritual. Pretendemos investigar como, especificamente, as teorias artísticas chinesas compreenderam a noção de um princípio inspirador ou moldador da obra de arte que é entendido como 'espírito', ou seja, que está ligado às crenças religiosas chinesas sem que, no entanto, isso torne toda a arte chinesa estritamente religiosa. Nossa proposta, pois, é compreender como as expressões artísticas chinesas podem significar um meio de intercâmbio entre dois mundos - 0 mundo material, ou “mundo da mutação" (Yi 易) e o mundo espiritual, estabelecendo um diálogo entre as duas instâncias. Buscaremos centrar nossa análise nas tradições artísticas do período Zhou 周 (1046-256 AEC), quando essas definições foram fixadas textualmente. Foi a partir de Confúcio 孔夫子 (551-479 AEC) que houve uma estruturação formal dos cânones literários, possibilitando realizar a análise que propomos agora. Lembremos, porém, o problema em estabelecer uma marcação mais precisa em termos cronológicos, tendo em vista ser essa uma história conceitual de longa duração.

Nossa trajetória nesse artigo será, primeiramente, descrever o papel da construção da escrita como forma de evocação espiritual por imagens, de acordo com o entendimento chinês sobre o surgimento de suas formas de expressões logogramáticas. Ao longo desse item, iremos apresentar fragmentos dos pensadores Zhou que comentaram a questão da escrita e da pintura. Em seguida, analisaremos o surgimento de códigos de expressão imagética no Yijing 易經 (o Tratado das Mutações), cujas representações personificam a evolução das ideias evocativas. Em um terceiro momento, discutiremos a ritualização dos saberes na China antiga, a partir da elaboração de cânones escritos que explicam a conexão entre palavras e ideias. Por fim, apresentaremos nossa conclusão, ilustrando com uma passagem pitoresca contemporânea o "sistema" de compreensão da arte pictórica chinesa. 
ISSN 1982-8713

\section{A Arte da Evocação}

Zhang Sengyou pintara quatro dragões numa parede. Nada faltava aos dragões: possuíam oitenta e uma vértebras, divididas em nove séries de nove, número este altamente benéfico. Ostentavam também longos bigodes de fogo de cada lado das faces e, no alto da cabeça, os cornos, sem o qual não poderiam voar pelos céus. Mas o pintor não lhes pusera os olhos. Perguntaram-lhe o motivo de tal omissão. Disse ele, suspirando:

- Já que o desejais..

Tomando um pincel, traçou os olhos dos dragões, que logo eriçaram seus cornos, saltaram da parede, franquearam a janela e desapareceram no céu. (apud Bueno, 2011, p.15)

A pequena historieta de Zhang Sengyou 张僧䋣, famoso pintor do período Liang 梁 (502-587 EC), e tomada aqui como exemplo, nos revela o aspecto evocador da arte chinesa: a capacidade de 'trazer a vida' um objeto material pela manifestação de seu 'princípio vital'. É claro, trata-se apenas de uma história (embora Zhang tenha sido de fato um famoso pintor), mas que nos explica a concepção chinesa de que o artista não é propriamente um criador, mas um 'revelador' de formas. Para entendermos isso, precisamos recorrer às origens de uma das primeiras expressões artísticas chinesas, a escrita, e suas profundas ligações com as crenças religiosas dessa civilização (Bueno, 2010a, p.23-33; Alleton, 2010, cap.4).

A escrita chinesa surgiu para dialogar com os espíritos (Vandermeersch, 2003). Os primeiros indícios da escrita aparecem nos oráculos em carapaças de tartaruga e patelas bovinas da Dinastia Shang 商 (1600-1046 AEC), mostrando a elaboração de códigos imagéticos com o fim de realizar predições. A consulta ao oráculo se dava da seguinte forma: eram gravadas duas frases, tanto num osso ou na carapaça, sendo uma afirmativa e outra negativa. Uma ponta de metal aquecida era inserida no corpo do oráculo, gerando uma rachadura que se dirigiria para uma das frases, propiciando assim a previsão. Isso aconteceria pela intercessão dos espíritos que acompanhavam os consulentes, intercedendo no curso da rachadura. 
As palavras escritas, pois, representava imagens que evocavam ideias, ou seja, o princípio vital pelo qual elas operariam. Para entendermos isso de modo mais simples, vejamos essa figura:

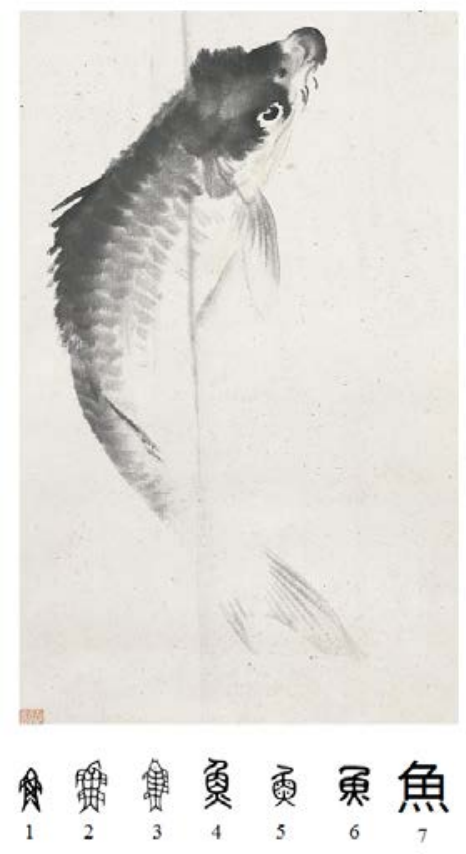

Figura 1: Evolução do Pictograma Peixe (Yu). Pintura de Peixe de Xu Beihong (徐悲鴻, 1895-1953). Caracteres chineses: 1.Escrita oracular da época Shang; 2 e 3.Escrita em bronze do período Zhou; 4.Escrita em selo ou documental, período Zhou; 5.Escrita cursiva, período Zhou; 6.Escrita cursiva, período Qin; 7.Forma atual. Disponível em http://www.chinaonlinemuseum.com/painting-fish-xubeihong.php. Acesso em 5 de maio de 2020.

Se perguntarmos a alguém o que essa imagem representa, é provável que responda, de imediato: 'é um peixe'. No entanto, sabemos que isso não é exatamente correto. Ela não se move, não tem cor, nem cheiro ou relevo. Desse modo, entendemos que essa imagem não é um peixe, mas a representação que evoca, em nossa mente, o peixe real (como referência, podemos ver o exercício de análise feito por Foucault [1973] sobre o cachimbo de Magritte). Para os chineses, isso implicava na possibilidade de evocarmos, por meio de imagens, a presença e a manifestação de um espírito (ou princípio vital) na matéria. 
NEARCD: Revista Eletrônica de Antiguidade 2020, Volume XII, Número II - ISSN IS82-8713

Núcleo de Estudas da Antiguidade - NEA

Universidade do Estado do Rio de Janeiro

ISSN 1982-8713

Na religião chinesa antiga, denominada de "Religião dos Espíritos" (Shenjiao 神 教), o mundo espiritual seria o verdadeiro "mundo real", sendo o mundo material (denominado 'mundo da mutação') a manifestação física dos princípios espirituais préexistentes. Estamos aqui diante de uma concepção similar a de Platão e seu mundo das ideias, mas a crença chinesa apresentava uma condição especial: o mundo espiritual continha as coisas em si, que tentaríamos manifestar nesse mundo material (Bueno, 2017).

O conceito Li 理 (Princípio, Estrutura) nos dá uma boa explicação para essa questão: ele representa a junção das palavras Pedra de Jade ( $Y$ U 玉) e 'campo arado' ou 'lavras' (Li 里). A pedra de jade, quando lapidada, deve ser talhada, aparada e polida seguindo a disposição de seus veios internos, sob o risco de se quebrar. Assim, quando um artista chinês olhava para uma pedra bruta, já era capaz de conceber a forma que dela derivaria, posto que a lapidação da mesma deveria seguir os veios aparentes. 0 princípio subjacente (ou ainda, vital) do que a pedra seria, pois, já estava contido na matéria bruta, esperando apenas ser revelado (Bueno, 2004). De fato, o conceito Li se tornou um elemento central do pensamento chinês, atravessando a história intelectual dessa civilização em vários campos (Rosker, 2012). O artista seria, assim, um "manifestador" do que já estaria contido na pedra, e sua originalidade e habilidade derivariam de sua capacidade interpretar essa imagem, e não de 'criá-la' de modo autêntico. Como afirmou o sinólogo Ricardo Joppert:

O termo chinês Yu 玉, que comumente se traduz por jade, no Ocidente, na verdade tem conotação mais ampla e abrange toda uma série de pedras especiais, capazes de serem esculpidas e polidas com fins estéticos, como o cristal-de-rocha, o quartzo, a calcedônia, a turquesa, a serpentina, a ágata, a malaquita... Além da textura, da coloração, das qualidades de tato e da sonoridade, conta, para os chineses, o desafio da estrutura interna da pedra. O desvendar da trama de veios, da granulação ou fibrosidade dos cristais, que exige toda uma pesquisa, para que da massa bruta surja a forma ideal, adequa-se á mente realista dos chineses. Esta sempre parte do concreto em direção a um núcleo, que, quando ainda não-visivel, tenha entretanto a possibilidade de ser revelado através de uma rota existente, de atalhos que possam ser tomados em busca da quintessência (Jing), da medula (Sui). 
ISSN 1982-8713

Resulta uma transparência que, ao adequar-se á luz exterior, mostra sempre a pureza interior da pedra, sua natureza fundamental, intrínseca. 0 trabalho do artista reveste-se, então, de significado simbólico, neste tipo de pedra que é Imagem, Ícone. (...) Tanto é assim que o logos chinês, o princípio de inteligibilidade do mundo, define-se pelo picto-ideograma Li, cujo significado primeiro é, justamente, o ordenameto da trama de veios internos do jade e das pedras que lhe são análogas (Joppert, 1996, p.12)

No pensamento chinês, a analogia da lapidação estende-se aos outros campos, incluso a pintura: a tela branca, de papel ou de seda, não constitui um espaço em branco para que nela se insira algo. Ela é o veículo pelo qual o artista manifesta uma imagem, que sua mente apreende em algum lugar (a paisagem, uma ideia, etc) e tenta extrair do vazio. Confúcio 孔夫子 (551-479 AEC), o grande sábio chinês, patenteia essa concepção nesse pequeno trecho, bastante elucidativo sobre a conexão ideia-imagem-pinturapalavras:

Zixia perguntou: O que significam estes versos?

Oh, as covinhas do sorriso dela!

Ah, o preto e branco de seus lindos olhos!

É sobre a seda puramente branca que as cores brilham.

O Mestre disse: A pintura se inicia na seda puramente branca.

Zixia perguntou: $O$ ritual é algo que vem posteriormente?

O Mestre disse: Ah, realmente abriste meus olhos! É apenas com um homem como tu que se podem discutir Poemas. (Lunyu 論語, 3:8)

Nesse fragmento, Confúcio sintetizava a razão das regras da pintura serem basicamente as mesmas da caligrafia. O material, pincel e tinta, eram os mesmos, assim como os propósitos da expressão - uma subjetividade aparente a ser revelada, manifestando o 'espírito' da obra. Na língua chinesa, a conexão etimológica entre essas ideias é profunda: pintar e desenhar (畫 Hua), pintura (畫畫 Huahua ou 繪畫 Huihua), livro (書 Shu) escrever (書寫 Shuxie) e caligrafar (書法 Shufa) tem o mesmo radical ordenador, apontando que a raiz das três é a mesma - lembremos, ainda, que 'desenhar' era utilizado como sinônimo de 'escrever', tendo em vista a morfologia da escrita chinesa (Harbaugh, 1999, p.401). 
NEARCD: Revista Eletrônica de Antiguidade 2020, Volume XII, Número II - ISSN IS882-8713

Núcleo de Estudas da Antiguidade - NEA

Universidade do Estado do Rio de Janeiro

ISSN 1982-8713

A pintura, assim como a escrita, serviam ao propósito de conectar ideias e imagens, como descreve uma outra passagem do pensador Hanfeizi 韓非子 (475-221 AEC):

Certa vez, um viajante foi contratado para pintar um painel de bambu para o Governante de Zhou, e demorou três anos para completá-lo. Quando o Governante o viu, parecia simplesmente um painel manchado de laca, e ficou furioso. Então o pintor disse: "Construa uma parede de seis metros e meio de altura com uma janela de dois metros de comprimento. Coloque o painel nele e, ao nascer do sol, olhe para ele". O Governante de Zhou seguiu as orientações, e quando olhou para o painel, da maneira como havia sido instruído, o encontrou se transformando em dragões, serpentes, pássaros, bestas, carruagens e cavalos, e inúmeras outras coisas. Ele ficou maravilhado. $\mathrm{O}$ trabalho realizado com este painel certamente foi delicado e difícil. No entanto, sua utilidade era a mesma de qualquer outro painel de bambu laqueado. (Hanfeizi 韓非子, 32:2)

Um comentarista posterior, Zhang Yanyuan 張彥遠 (815-877 EC), daria a seguinte interpretação sobre essas passagens:

A pintura completa a cultura, ajuda nas relações humanas e explora os mistérios do universo. Seu valor é igual ao estudo dos seis clássicos e, assim como a rotação das estações, provém da natureza, e não é algo dado somente pela tradição. Quando os antigos soberanos receberam o mandato do céu, inscrições em cascos de tartaruga e pinturas nos ossos de dragão apareceram. (...) Durante este período, a escrita não era substancialmente diferente das coisas que representava, mas suas formas ainda eram muito cruas. A escrita desenvolveu-se, então para expressar ideias, e a pintura nasceu do desejo de representar formas. Esta era a intenção e o propósito dos sábios. (...) Yen Guanglu (384 -456) disse: 'os propósitos dos desenhos são três: capturar o princípio (Li), como nos hexagramas; manifestar ideias, como na escrita; e desenhar as formas, representando-as. (apud Bueno, 2011, p.15)

\section{Expressões codificadas do Mundo da Mutação}

Como vimos no trecho acima, a relação do ato de desenhar/pintar para os chineses constituía a técnica de expressão do subjetivo, expresso pela manifestação das ideias, das formas e dos conceitos. Essa ultima consideração precisa ser igualmente abordada. Os chineses vinham aprofundando a ideia da intercessão espiritual em suas 
ISSN 1982-8713

elaborações imagéticas ao longo de todo o período Zhou. O livro das Mutações (Yijing 易 經), datado do século 12 AEC, constitui um amplo conjunto de registros das manifestações da natureza, que foram ordenados, por meio de um código, numa longa e detalhada sequência cíclica, representada através de um arranjo binário entre as linhas yin e yang, expressas respectivamente como ) el ). Os arranjos de seis linhas (hexagramas) formavam imagens completas, que estavam associadas analogamente a evocação de ideias. O Yijing tornou-se o primeiro manual de ciências chinesas, sendo a principal fonte para explicar os ciclos e tendências da natureza, bem como sua influência no cotidiano. Sua ascendência foi decisiva na estruturação do pensamento chinês na época Zhou (Correa, 2014). O historiador Bangu 班固 (32-92 EC), autor do Pavilhão do Tigre Branco (Baihutong 白虎通) nos apresenta a interpretação de algumas dessas imagens, comentadas pelo sinólogo alemão Richard Wilhelm (1873-1930):

7 - Eles amansaram o gado e atrelaram o cavalo. Assim, pesadas cargas puderam ser transportadas e regiões longínquas alcançadas, para benefício do mundo. Provavelmente inspiraram-se para isso no hexagrama a SEGUIR.

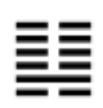

Comentário de Richard Wilhelm: O hexagrama Sui, SEGUIR (17), é composto de Tui, a jovialidade, adiante e Chen, o movimento, atrás; representam o boi e o cavalo adiante e a carroça movendo-se atrás. Os bois eram utilizados em carroças pesadas, e cavalos, em carruagens ligeiras e veículos de guerra. Na China, nos períodos mais remotos da antiguidade, desconhecia-se o uso do cavalo como montaria.(...)

9 - Eles partiram a madeira e com ela fizeram um pilão. Escavaram a terra para fazer um almofariz. $O$ uso do pilão e do almofariz beneficiou toda a humanidade. Provavelmente inspiraram-se para isso no hexagrama A PREPONDERÂNCIA DO PEQUENO. 
ISSN 1982-8713

Comentário de Richard Wilhelm: O hexagrama Hsiao Kuo, PREPONDERÂNCIA DO PEQUENO (62), é composto de Chên, movimento, madeira, acima e Kên, a imobilidade, pedra, abaixo. Kuo também significa transição. $O$ almofariz era o substituto primitivo do moinho; significa a transição do hábito de comer ainda o próprio grão para a utilização do forno.

10 - Eles encordoaram um pedaço de madeira e fizeram um arco; enrijeceram outro pedaço de madeira no fogo para fazer flechas. A utilidade do arco e da flecha consiste em manter o mundo atemorizado. Provavelmente inspiraram-se para isso no hexagrama OPOSIÇÃO.

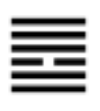

Comentário de Richard Wilhelm: O hexagrama K'uei, OPOSIÇÃO (38), é composto de Li, o Aderir, acima e Tui, a Alegria, abaixo. Os trigramas nucleares são $K^{\prime}$ an, perigo, e novamente Li. Todo o hexagrama indica luta. Li é o sol que de longe lança suas flechas. Li significa armas; K'an, o perigo. O perigo está cercado de armas, por isso não se está com medo.

(Wilhelm, 1986, p.254-256)

Como podemos observar por esses exemplos, a expressão imagética é a codificação de uma ação, cujo sentido é mental/espiritual. Tais como as antigas carapaças de tartaruga Shang, o Yijing também se tornaria um oráculo, servindo para predizer o futuro. A mente chinesa supôs que esse antigo sistema cosmológico poderia prever disposições e convergências, e mais uma vez, evocar os espíritos para que eles se comunicassem por meio de imagens. Numa compreensão mais moderna, essa ordenação cosmológica levou a elaboração de uma teoria interpretativa sobre a natureza, sistematizando a compreensão do processo criativo (Jullien, 2018, p.109-27). 
NEARCD: Revista Eletrônica de Antiguidade 2020, Volume XII, Número II - ISSN IS882-8713

Núclea de Estudas da Antiguidade - NEA

Universidade do Estado do Rio de Janeiro

ISSN 1982-8713

A concepção de que a imagem manifestava ou corporificava princípios espirituais motivou Confúcio a aprofundar sua pesquisa com palavras escritas, concluindo que a desordem no mundo da mutação era provocada pela interpretação equivocada ou desviada das mesmas. Por essa razão, ele insistiu com veemência na questão da 'Retificação dos Nomes' (Zhengming 正名). Para ele, estava claro que se as palavras fossem usadas de forma polissêmica, elas perderiam seus sentidos, e deixaram de evocar as ideias que representavam (Vandermeersch, 1993). Confúcio estava consciente de que a escrita chinesa era logográfica, ou seja, que representava retratos (pictogramas) ou elaborações (ideogramas) cujos sentidos derivavam justamente de seus princípios vitalizantes. Mudar o sentido de uma palavra, portanto, seria matá-la, esvaziá-la, gradualmente perdendo o contato com toda a literatura e o conhecimento dos antigos, com profundas implicâncias políticas (Levi, 1993) e culturais:

\begin{abstract}
Zilu perguntou: "Se o dirigente de Wei vos confiasse o governo do país, qual seria vossa primeira iniciativa?" O Mestre disse: "Por certo seria retificar os nomes". Zilu disse: "Realmente? Isso não é um pouco forçado? De que serve a retificação?" O Mestre disse: "Como podes tornar-te grosseiro! Sobre aquilo em que um cavalheiro é incompetente, ele deve permanecer calado. Quando os nomes não são corretos, a linguagem fica sem sentido. Quando a linguagem fica sem sentido, nenhum assunto pode ser resolvido. Quando nenhum assunto pode ser resolvido, os ritos e a música cessam. Quando os ritos e a música cessam, punições e penalidades erram o alvo. Quando punições e penalidades erram o alvo, as pessoas não sabem onde estão. Por isso, aquilo que um cavalheiro concebe, ele tem de ser capaz de dizer; e aquilo que ele diz, ele tem de ser capaz de fazer. No que se refere à linguagem, um cavalheiro não deixa nada ao acaso". (Lunyu 論語, 13:3)
\end{abstract}

Embora a 'Retificação dos Nomes' tenha sido defendida enfaticamente por Xunzi 荀子 (310-235 AEC), ela se mostraria inviável. Todavia, a teoria serviu para construir um sistema etimológico importante, baseado no grafismo (e não na grafia). Portanto, o artista chinês antigo - pintor e calígrafo ao mesmo tempo - era entendido como um evocador de almas, de uma essencialidade oculta, que marcam a ideia de revelação por meio da expressão imagética. Zhuangzi 莊子 (369-286 AEC), o conhecido pensador 
NEARCD: Revista Eletrônica de Antiguidade 2020, Volume XII, Número II - ISSN IS882-8713

Núcleo de Estudas da Antiguidade - NEA

Universidade do Estado do Rio de Janeiro

ISSN 1982-8713

daoísta depois de Laozi 老子(séc. 6 AEC), deixou ainda mais claro o aspecto profundo e reflexivo do artista, colocando-o num plano meditativo para a manifestação das coisas:

\begin{abstract}
O duque Yuan de Song quis que um mapa fosse produzido, e convocou todos os mestres do pincel para realizarem a tarefa, que acorreram ao chamado. Tendo recebido as instruções do projeto, eles começaram a se aprontar, lambendo seus pincéis e preparando a tinta. Metade deles, no entanto, ficou de fora. Mas houve um que veio tarde, com um ar de indiferença, e não tinha pressa para nada. Depois de receber as instruções, nem mesmo parou em pé, mas foi para um galpão retirado. O duque enviou um homem para vê-lo, e ele estava lá, com seu manto deixado de lado, sentado de pernas cruzadas, quase nu, e de olhos fechados. O governante disse: "Ele é o homem; ele é um pintor verdadeiro!" (Zhuangzi 莊子, 21:7)
\end{abstract}

\title{
A Ritualização dos Saberes
}

A concepção de que a arte expressava manifestações advindas do plano espiritual foi reforçada pela interpretação do ideograma Li 禮 (Rito, Cultura), que representa a junção da palavra Shi 示 (revelação), ligada a Shen 神 (espírito, alma) e Qu 曲 (oferenda) com Dou 豆 (vaso de bronze), ou seja: uma "oferenda para a alma", ou "oferenda por revelação, comunicação com os espíritos" (daí porque ela foi traduzida como 'Ritual' por vários sinólogos). As práticas culturais fundamentais da sociedade chinesas eram simbolizadas por uma oferenda aos espíritos, aos ancestrais que construíram a civilização e que, porventura, poderiam continuar atuando na existência humana (Poo, 2009). No Liji 禮記, a origem de Li está ligada a interpretação religiosa da vida:

Li tem sua origem na Unidade Primeira, que se dividiu em Céu e Terra, transformando-se em yin e yang, atuando através das estações do ano e tomando forma segundo os diferentes espíritos. A vontade dos deuses manifesta-se como destino, sob controle do Céu. Assim deve Li ter o Céu por fundamento, exerce na Terra a sua ação e aplica-se às diferentes atividades humanas, mudando de acordo com as estações do ano e os vários ofícios. No ser humano, Li surge como princípio vital e manifesta-se no trabalho, no comércio, no convívio social, no comer e no beber, na cerimônia da "investidura" do que atinge à maioridade, no casamento, nos funerais e nos 
NEARCD: Revista Eletrônica de Antiguidade 2020, Volume XII, Número II - ISSN IS82-8713

Núcleo de Estudas da Antiguidade - NEA

Universidade do Estado do Rio de Janeiro

ISSN 1982-8713

sacrifícios aos mortos, na carreira das armas, na condução de veículos, e nas audiências em palácio. (Liji 禮記, cap.9)

O "Rito", ou as "práticas culturais", significam, simbolicamente, um objeto artístico com fins devocionais. No plano cultural, o sentido de Li disseminara-se em todas as estâncias, dando-lhes ordenação. No caso específico de vasos de bronze, eles adquiriram um caráter sacro, pela sua associação com as oferendas funerais (Thote, 2003). Por essa razão, Confúcio reclamou quando alguém tentara modificar o sentido da palavra 'Vaso quadrado' (Gu 解): 'Vaso que não é vaso? É vaso!' (Lunyu, 6:25)

Mesmo nas tumbas, o uso da evocação escrita e imagética era amplamente utilizado. As pinturas encontradas na tumba do Marques Yi (Strassberg, 2002, p.59-62) e em tumbas Han (Suhaudolnic, 2014, p.219-51) nos revelam o amplo emprego de símbolos mágicos, animais do zodíaco, espíritos protetores, entre outros, destinados a proteger a caminhada do defunto em direção as "Terras das Primaveras Amarelas" (Huangquan 黄泉, um dos nomes comuns do mundo dos espíritos). De acordo com Wu Hung, a imagem do morto era pintada no sarcófago, conectando magicamente a imagem com o espírito, como veremos adiante (Wu, 1999, p.743-4), e padrões imagéticos codificados estavam presentes nas tumbas (Thote, 2004). Estamos aqui diante do clássico paradoxo lançado pelo já citado pensador Zhuangzi, mas agora, sobre a questão das múltiplas existências:

Certa vez eu, Zhuang Zhou 莊周, sonhei que era uma borboleta, adejando daqui para acolá, com todos os fins e propósitos de uma borboleta. Só tinha consciência de minha felicidade como borboleta sem saber que eu era Zhou. Depressa acordei e ali estava eu, eu mesmo, na verdade. Agora não sei se eu era um homem sonhando ser borboleta, ou se eu sou uma borboleta sonhando ser um homem. Entre um homem e uma borboleta há, naturalmente, uma distinção. A transição é chamada transformação de coisas materiais. (Zhuangzi 莊子, cap.2)

Zhuang propunha que poderíamos ter inúmeras vidas, concomitantes ou não, que se entrelaçariam e se fundiriam. Do mesmo modo, os artistas das tumbas 
ISSN 1982-8713

pressupunham, assim, que suas decorações, objetos e estátuas manifestavam espíritos evocados, que voltariam para o mundo espiritual sob a guarda do dono da tumba após seu sacrifício ritual. Ao menos, era o que eles esperavam.

\section{Análise de caso: $O$ Cavalheiro cavalga o dragão}

No período que nos propusemos a analisar, há um conjunto suficiente de referências textuais e teóricas; todavia, não são muitas as pinturas disponíveis para análise. Isso ocorre por diversas razões: uso de materiais perecíveis, destruições, reciclagem de bases e suportes, entre outras razões. Algumas pinturas puderam ser resgatadas de tumbas, como a que nos propomos apresentar a seguir.

O Cavalheiro cavalga o dragão foi encontrada numa tumba em Zidanku 子彈庫, distrito de Changsha 長沙, na província de Hunan 湖南, datando do século 3AEC. Na época, essa região pertencia ao Reino de Chu 楚, depois incorporado ao império Qin 秦 . A análise dessa pintura foi feita por Wu Hung (idem Wu, 1999, 743-4 e 2002, 21-3), e nos mostra a conexão evocativa da pintura com a ideia de sobrevivência espiritual. 


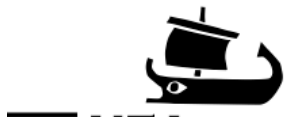

回 NEARCO

Revista Eletrônica de

Antiguidade e Mediev
NEARCD: Revista Eletrônica de Antiguidade 2020, Volume XII, Número II - ISSN 1982-8713

Núclea de Estudas da Antiguidade - NEA

Universidade do Estado do Rio de Janeiro

ISSN 1982-8713
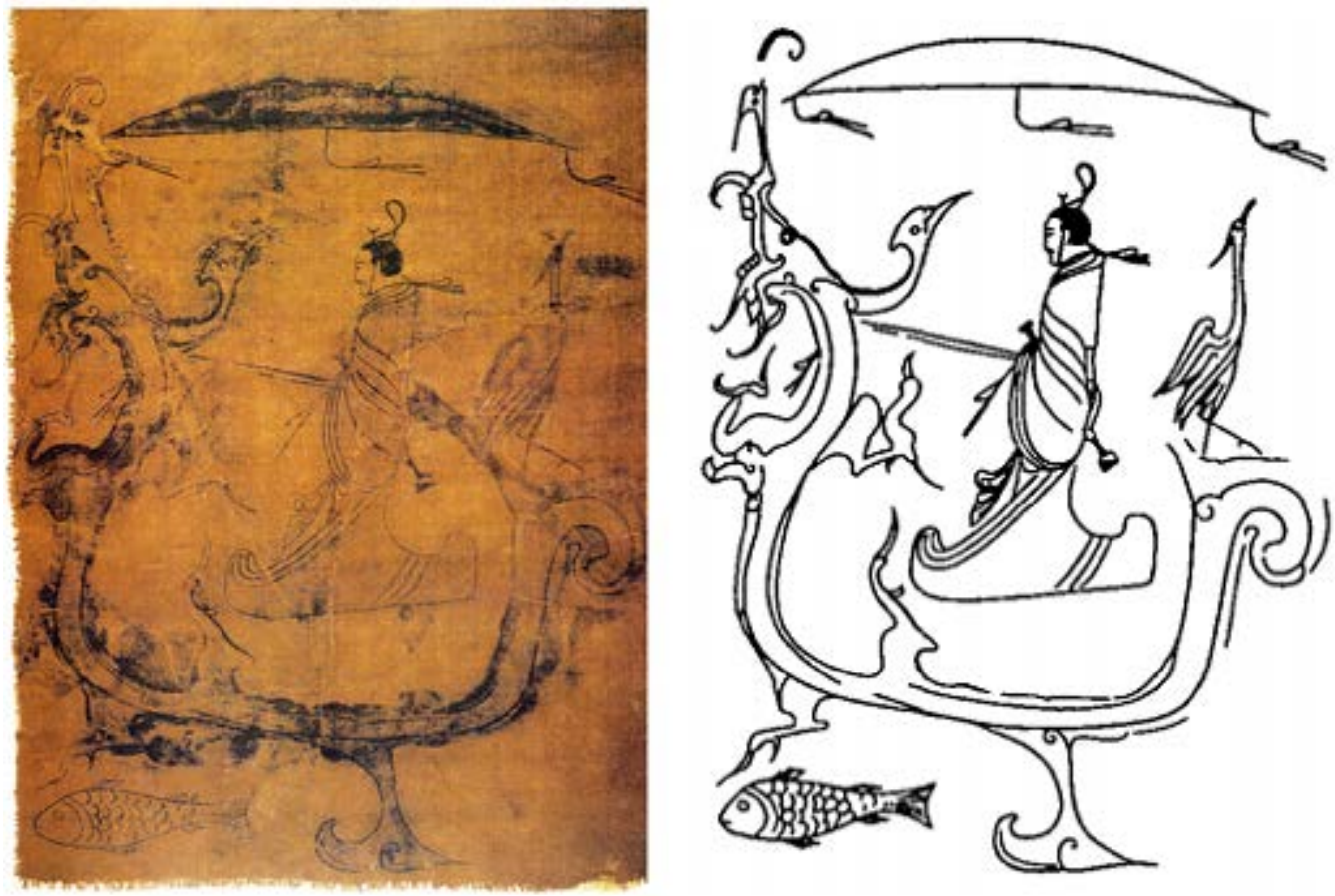

Figura 2: O cavalheiro cavalga o dragão. Referência: WU, 2002, p.22; 1999, p.743.

A pintura foi encontrada na tumba de um 'cavalheiro' ( \pm Shi), que levara consigo um coleção de textos em seda, considerada um importante achado sobre o pensamento cosmológico, astronômico e divinatório da China antiga (Li, 2019). Wu descreve a pintura da seguinte maneira:

A posição sobre a imagem masculina de Zidanku é definitiva: de acordo com o relatório da escavação, essa pintura foi descoberta com a face voltada para cima sobre o caixão. Nesta posição, correspondia estreitamente ao cadáver dentro do caixão. A identidade dessa pintura como retrato do ocupante do túmulo é confirmada por duas evidências adicionais: primeiro, como o cavalheiro da pintura, o falecido era um homem de meia idade; segundo, a espada de bronze usada pelo falecido se assemelha à usada pelo cavalheiro na pintura. Com uma vara de bambu fina fixada na borda superior e uma fita presa no meio do bastão, presumivelmente essa pintura foi pendurada durante o ritual funerário antes de ser enterrada; essa evidência confirma novamente a identidade dessa pintura como uma faixa de nome. [...] A figura em cada trabalho é o foco de uma grande composição, que inclui outras imagens para representar uma situação específica [...] mas uma opinião dominante é que as imagens representam a transformação da alma. A evidência mais forte para esse argumento é que parecem fazer uma jornada 
ISSN 1982-8713

celestial: o homem está dirigindo um dragão ou um barco de dragão. Animais e pássaros adicionais acompanham [as] figuras [...] uma carpa está nadando ao lado do barco dragão do cavalheiro, enquanto uma apara sustenta a cauda do dragão. Muito foi escrito sobre o poder mágico dessas criaturas em ajudar uma pessoa a alcançar a imortalidade [...] O pintor do retrato do cavalheiro, por outro lado, tinha um controle muito melhor do pincel e um objetivo artístico mais alto. Não apenas ele poderia lidar com tarefas mais difíceis na representação de seu sujeito, com uma representação convincente e sutil do ombro redondo da figura, seu gorro delicado e sua expressão facial suave, mas suas linhas de tinta assumiram uma espécie de valor estético independente, uma vez que podem ser apreciadas por sua suavidade, fluidez, dinamismo e configuração harmoniosa. De fato, esta pintura fornece um excelente exemplo do estilo de desenho chamado "fios de seda flutuantes da antiguidade" (gaogu yousi miao 高古遊糸描), que seria seguido e elogiado por artistas e críticos de arte de épocas posteriores (Wu, 1999, p.743-4).

A análise dessa pintura congrega todos os elementos apresentados anteriormente: em primeiro lugar, todos os pertences do defunto estão associados a sua imagem pintada; a apresentação da mesma evoca sua presença na tumba, e a associação com o seu espírito livre do corpo físico (razão pela qual ladrões de tumbas tinham medo de ações espirituais punitivas por parte dos donos); a disposição das representações é sistematizada dentro de um esquema ritualizado, previsto nas orientações funerais do Liji (cap.22). Assim, o que a pintura nos traz é a ideia de que as conexões entre o mundo da mutação e o mundo espiritual seguem determinadas regras, pelas quais as expressões imagéticas podem desempenhar seus papéis. Se na escrita essas associações foram codificadas ao longo de século pela estrutura gráfica logogramática, na pintura (em específico) elas poderiam, também, invocar figuras ou ações específicas.

\section{Conclusões}

Essa breve explanação buscou demonstrar como os chineses compreendiam o papel da escrita e da pintura como uma forma de arte espiritualizada, concepção que se consolidou claramente no período Zhou. Poderíamos dizer, assim, que a arte chinesa seria, de certa maneira, "religiosa". Todavia, ela não se limitou a expressar motivos 
ISSN 1982-8713

religiosos, e nisso constitui a armadilha de tentar classificá-la como uma arte essencialmente sagrada. Por mais notável que pareça, a crença do artista chinês, que buscava imaginar e compreender a "alma" de uma obra de arte escondida na matéria, e que poderia manifestá-la numa paisagem, numa palavra ou em um objeto mundano, sem qualquer aplicação ou conotação religiosa direta, revela a elaboração de um entendimento "espiritualizado" e sistêmico sobre a arte, mas que não atendia somente ao cerimonial religioso.

A preocupação chinesa pareceu centrar-se em dominar os mecanismos de evocar esses 'espíritos' ou 'princípios vitais' (Li 理) que estruturavam a constituição de uma peça ou de uma pintura em seu estado bruto, num processo de subjetividade aparente. O exercício do artista chinês consistia em interagir continuamente com os materiais brutos de modo a descobrir as imagens nela ocultas, e de manifestá-las de tal maneira que todos pudessem acessar a ideia nela representada. No mesmo sentido, o domínio das formas e meios de expressão permitia o contato com o mundo espiritual, numa via de mão dupla. Caligrafia e a Pintura seriam então herdeiras diretas do contato com os espíritos, como formas desenvolvidas de psicopictografias.

O processo sutil de criação da mente artística chinesa desenvolveu-se assim, desde a antiguidade, adquirindo um nível de percepção estética e sensorial desconhecido por nós. Para finalizar essa apresentação, mostrando a continuidade dessas concepções na mentalidade chinesa, gostaríamos de ilustrar uma passagem do livro de José Roberto Leite, A China no Brasil. Conta-nos o autor a história do pintor chinês Zhang Daqiang 张大千 (Chang Dai Chien, 1889-1983), que viveu por alguns anos no Brasil, em Mogi das Cruzes (1954-70). Amigo de Picasso, o pintor possuía um grande domínio da habilidade "evocadora" de princípios vitais que animavam a construção da obra de arte: 
quadros para que Picasso os autenticasse. O artista espanhol percebeu que havia um falso entre os trabalhos apresentados, e para testar Chang, perguntou-lhe se seria capaz de distinguir, entre os quadros autênticos, a falsificação. O chinês, sem se fazer de rogado, imediatamente apontou para o quadro falso, dizendo: 'não sinto aqui o seu qi' (espírito, sopro vital) (Leite, 1999, p.199)

Ainda há um longo caminho, pois, para compreendermos os fundamentos da arte chinesa desde a antiguidade.

\section{Referências}

\section{Documentação:}

CONFÚCIO. "Liji" in Lin, Yutang. Sabedoria de Confúcio. Trad. Geir Campos. 1a Ed. Rio de janeiro: José Olympio, 1958.

CONFÚCIO. Analectos. Trad. Simon Leys. 1a Ed. São Paulo: Martins Fontes, 2009. (Lunyu)

CONFúCIO. I Ching, o livro das mutações. Trad. Richard Wilhelm. 2a Ed. São Paulo: Pensamento, 1986. (Yijing)

HANFEIZI. The complete works of Han Fei Tzu. Trad. W. K. Liao. 1a Ed. London: A. Probsthain, 1939.

ZHUANGZI. "Chuangtzu" in Lin, Yutang. Sabedoria de Índia e China. Trad. Sodré Vianna. 2a Ed. Rio de janeiro: Pongetti, 1958.

ZHUANGZI. Chuangtzu: ensinamentos essenciais. Org. por Sam Hamill e J. P. Seaton. Trad. Eduardo Pereira e Ferreira. 1ạ Ed. São Paulo: Cultrix, 2000.

\section{Bibliografia}

ALLETON, Viviane. A escrita chinesa. Trad. Paulo Neves, 1aㅡ. Ed. Porto Alegre, LPM, 2010.

BARNES, Gina. The Rise of Civilization in East Asia: The Archaeology of China, Korea and Japan. 2a ed. New York: Thames \& Hudson, 1999.

BUENO, André. "A religião dos Espíritos na China Antiga". In DIAS, Carolina Kesser; 
CORSI, Semiramis e CAMPOS, Carlos Eduardo. (eds.) Experiências religiosas no mundo antigo. 1.ed. Curitiba: Editora Prismas, 2017. Vol. 1, p. 31-49.

BUENO, André. "A evolução do pensamento religioso chinês" in BUENO, André. Em busca do Palácio Celeste. Projeto Orientalismo: União da Vitória, 2010a.

BUENO, André. "O mundo nos veios de um jade". Lisboa: revista Crítica na Rede, 2004. Disponível em: http://criticanarede.com/est_jade.html Acessado em 14/02/2020.

BUENO, André. Caderno de Rabiscos. Projeto Orientalismo: União da Vitória, 2011.

BUENO, André. Mirações do Celeste. Projeto Orientalismo: União da Vitória, 2010b.

CORREA, Jesualdo. "Reflexões genealógicas e circulares sobre a formação do pensamento chinês antigo". Bueno, André e Neto, José M. Antigas Leituras: Visões da China Antiga. 1a Ed. União da Vitória: Unespar/Upe, 2014, p.156-177.

FALKENHAUSEN, Lothar von. "Action and Image in Early Chinese Art". In: Cahiers d'Extrême-Asie, vol. 17, p. 51-91, 2008.

FOUCAULT, Michel. Isto não é um cachimbo. Trad. Jorge Coli. 1a Ed. Campinas: Unicamp, 1973.

HAN, Byung-Chul. Shanzhai: el arte de la falsificación y la deconstrucción en China. Trad. Paula Kuffer. 1a Ed. Buenos Aires: Caja Negra, 2016.

HARBAUGH, Rick. Chinese Characters: A Genealogy and Dictionary. Yale: Yale University Press, 1999.

JOPPERT, Ricardo. Curso de história da porcelana chinesa: Estudos teóricos e práticos de obras de arte fascinantes. Rio de Janeiro: Rumo certo, 2015.

JOPPERT, Ricardo. O Samadhi em verde e azul. Rio de janeiro: Avenir, 1984.

JOPPERT, Ricardo. Oposição complementar. Rio de Janeiro: Museu Castro Maya, 1996.

JULLIEN, François. Processo ou criação. Trad. Mariana Echalar. 1a Ed. São Paulo: UNESP, 2019.

LEITE, José Roberto. A China no Brasil: influências, marcas, ecos e sobrevivências chinesas na sociedade e na arte brasileiras. Campinas: Unicamp, 1999. 
LEVI, Jean. "Quelques aspects de la rectification des noms dans la pensée et la pratique politiques de la Chine ancienne". In: Extrême-Orient, Extrême-Occident. N. 15, pp. 2353, 1993.

LEYS, Simon. Ensaios sobre a China. Trad. António Gonçalves. 1a Ed. Lisboa: Cotovia, 2005.

LI, Ling. The Chu Silk Manuscripts from Zidanku, Changsha (Hunan Province): Volume One: Discovery and Transmission. Trad. Lothar Falkenhausen. 1a ed. Beijing: Chinese University Press, 2019.

LI, Zehou. Path of Beauty: A Study of Chinese Aesthetics. Beijing: China Books Press, 1989.

LIN, Yutang 林語堂. The Chinese Theory of Art. London: Putnam's sons, 1967. LION-GOLDSCHMIDT, Daisy \& MOREAU-GOBARD, Jean-Claude. Chinese Art: Bronzes, Jade, Sculpture, Ceramics. Trad. George Savage. 1a ed. London: Phaidon Press, 1980.

POO, Mu-Chou. Ritual and ritual texts in early China. in KALLINOSWKI, Marc e LAGERWEY, John [ed.] Early Chinese Religion: Part One: Shang Through Han (1250 BC220 AD). Leiden: Brill, 2009, p.281-314.

PORTAL, Jane (ed.). The First Emperor: China's Terracotta Army. London: British Museum, 2007.

ROSKER, Jana. Traditional Chinese Philosophy and the Paradigm of Structure (Li). Cambridge: Cambridge Scholars Publishing, 2012.

SCARPARI, Maurizio. A China antiga. Trad. Alexandre Martins. 1ạ Ed. São Paulo: Folio, 2006.

SINEDINO, Giorgio. "Entre Artes Liberais e Liuyi (Seis Artes): Um Esboço de Certas Peculiaridades da Concepção Chinesa de "Arte" na Dinastia Han" in Revista de Cultura (Instituto Cultural de Macau), vol. 48, p.135-138, 2015.

STRASSBERG, Richard. A Chinese bestiary. Berkeley: University of California Press, 2002.

SUHADOLNIC, Natasa. "Os quatro animais cosmológicos em tumbas Han com animais" em BUENO, André. e NETO, José M. Antigas Leituras: Visões da China Antiga. Trad. André Bueno. 1ạ Ed. União da Vitória: Unespar/Upe, 2014, p. 219-250.

THOTE, Alain. "Du message à l'image: le décor des bronzes Shang et Zhou, XVe-Ille s. 
av. J.-C.". In: Arts asiatiques, tome 58, 2003. p. 73-85.

THOTE, Alain. "Ritual practices as Seen the Ruler's Tombs of the Eastern Zhou Period: Patterns and Regional Traditions". in LAGERWEY, John [org.] Religion and Chinese Society, vol. 1: Ancient and Medieval China. Hong Kong: Chinese University of Hong Kong/École française d'Extrême-Orient, 2004, p. 65-108.

VANDERMEERSCH, Leon. 'Idéographie chinoise et divination'. in: Actes du premier forum international du Centre de Calligraphie de la Bibliotheca Alexandrina, 24-27 avril. Paris: Bibliotheca Alexandrina, p.81-96, 2003. Disponível em: http://www.ceei.univparis7.fr/04_bibliotheque/01/pdf/05_Leon_Vandermeersch.pdf. Acessado em 14/02/2020.

VANDERMEERSCH, Léon. "Rectification des noms et langue graphique chinoises". In: Extrême-Orient, Extrême-Occident N.15. p. 11-21, 1993.

WATSON, William. The Arts of China to A.D. 900. Yale: Yale University Press, 2000.

WATSON, William. China Antiga. Trad. Tomé Santos Jr. 1a Ed. Lisboa: Verbo, 1969.

WU, Hung. "The Art and Architecture of the Warring States Period" in LOEWE, Michael e SHAUGHNESSY, Edward. (ed.) The Cambridge History of Ancient China: From the Origins of Civilization to 221 BC. Cambridge: Cambridge University Press, 1999, p.742744.

WU, Hung. "Early paintings..." in BARNHART, Richard et alli. Three Thousand Years of Chinese Painting. Yale: Yale University press, 2002. 